\title{
Thermal Study of a Newly Synthesized Cu(II) Complex Binding to Bovine $\beta$-Lactoglobulin
}

\author{
Adeleh Divsalar, ${ }^{1,2}$ Lyla Barzegar, ${ }^{3}$ and Gholamreza Rezaei Behbehani ${ }^{4}$ \\ ${ }^{1}$ Institute of Biochemistry and Biophysics, University of Tehran, Tehran, Iran \\ ${ }^{2}$ Department of Biological Sciences, Tarbiat Moallem University, Tehran, Iran \\ ${ }^{3}$ Chemistry Department, Faculty of Science, Islamic Azad University, Takestan Branch, Takestan, Iran \\ ${ }^{4}$ Chemistry Department, Imam Khomeini International University, Qazvin, Iran
}

Correspondence should be addressed to Gholamreza Rezaei Behbehani; grb402003@yahoo.com

Received 5 June 2012; Revised 30 July 2012; Accepted 13 August 2012

Academic Editor: Yehia Mechref

Copyright (C) 2013 Adeleh Divsalar et al. This is an open access article distributed under the Creative Commons Attribution License, which permits unrestricted use, distribution, and reproduction in any medium, provided the original work is properly cited.

\begin{abstract}
We have investigated the interactions between $\beta$-lactoglobulin, BLG, and new synthesized $\mathrm{Cu}$ (II) complex (2,2'-dibipyridine $\mathrm{Cu}$ (II) chloride) using isothermal titration calorimetry (ITC) methods at different temperatures of 298 and $310 \mathrm{~K}$. The heats of $\mathrm{BLG}+\mathrm{Cu}(\mathrm{II})$ interactions are reported and analyzed in terms of the extended solvation theory for calculation of binding and thermodynamic parameters of the interaction. The results suggested that binding of $\mathrm{Cu}$ (II) complex on BLG resulted in significant changes on the tertiary structure and conformation of protein via increasing of hydrophobicity and inducing partially unfolded structure in BLG which has a good agreement with the solvation parameters recovered by the extended solvation model suggesting destabilization of the protein.
\end{abstract}

\section{Introduction}

Milk proteins consist of caseins (78.3\%), whey proteins (19\%), and miscellaneous proteins (2.7\%) [1]. Whey proteins are widely used in formulated foods because they have high nutritional value and excellent functional properties. Whey proteins, which include serum albumin, immunoglobulins, $\alpha$-lactalbumin, and $\beta$-lactoglobulin (BLG), are more reactive because they dissolve in the serum. BLG, the major protein in whey, is responsible for most of the bioactive properties of whey proteins. Due to their emulsifying, interfacial, and gelation properties, tryptic peptides from whey proteins are of great interest to the food industry. BLG composed of 162 amino acid residues and two disulfide bonds (Cys66Cys160 and Cys106-Cys119) belongs to the lipocalin protein family $[1,2]$. At physiological $\mathrm{pH}, \mathrm{BLG}$ is mostly found as dimers, and at $\mathrm{pH}$ values below 3.5 and above 7.5 , the protein tends to be monomeric [3]. BLG solutions form gels in various conditions, when the native structure is sufficiently destabilised to allow aggregation. As milk is a known allergen, manufacturers need to prove the presence or absence of $\beta$-lactoglobulin to ensure that their labelling satisfies the requirements of the aforementioned directive. Food testing laboratories can use ELISA (enzyme-linked immunosorbent assay) methods to identify and quantify $\beta$-lactoglobulin in food products [4-11].

Copper is an essential trace element for all biological organisms, from bacterial cells to humans. There are eight negative charges on the surface of BLG in neutral $\mathrm{pH}$ conditions, which may be sites for binding positively charged metal ions $[12,13]$.

Since BLG is one of the most important milk carrier proteins and has great ability for binding to different drugs, specially cancer chemotherapy drugs, then it may has a central role in the molecular pharmacology of drugs used in cancer chemotherapy [14]. Then, in the present study, we have decided to investigate the binding of a new synthesized $\mathrm{Cu}$ (II) complex (2,2'-dibipyridine $\mathrm{Cu}$ (II) chloride), with milk carrier protein of BLG at different temperatures of 298 (room temperature) and $310 \mathrm{~K}$ (physiologic temperature) (upper fever temperature) using calorimetric (ITC) methods of the extended solvation theory. 


\section{Materials and Method}

The isothermal titration calorimetric experiments were carried out on a VP-ITC ultrasensitive titration calorimeter (MicroCal, LLC, Northampton, MA). The microcalorimeter consists of a reference cell and a sample cell of $1.8 \mathrm{~mL}$ in volume, with both cells insulated by an adiabatic shield. All solutions were thoroughly degassed before use by stirring under vacuum. The sample cell was loaded with BLG solution $(47 \mu \mathrm{M})$, and the reference cell contained $\mathrm{NaCl}$ solution. The solution in the cell was stirred at $307 \mathrm{rpm}$ by the syringe (equipped with micropropeller) filled with $\mathrm{Cu}(\mathrm{II})$ complex solution $(1.5 \mathrm{mM})$ to ensure rapid mixing. The titration of protein with $\mathrm{Cu}$ (II) complex solution involved 30 consecutive injections of the copper solution, the first being $5 \mu \mathrm{L}$, and the remaining ones of $10 \mu \mathrm{L}$. In all cases, each injection was done in $6 \mathrm{~s}$ at 3-minute intervals. To correct the thermal effects due to $\mathrm{Cu}$ (II) complex dilution, control experiments were done in which identical aliquots were injected into the $\mathrm{NaCl}$ solution in the absence of BLG. The measurements were performed at constant temperatures of 298.00 and $310.00 \pm 0.02 \mathrm{~K}$, and the temperature was controlled using a Poly-Science water bath. The data were collected automatically, and the heat of interaction between $\mathrm{BLG}+\mathrm{Cu}(\mathrm{II})$ complex was subtracted from heat of $\mathrm{Cu}$ (II) complex dilution. The measured heats of binding have been shown graphically in Figure 1.

\section{Results and Discussion}

It has been reported previously [15-23] that the heats of interactions of biopolymers with ligands (BLG-A $+\mathrm{Cu}$ (II) complex in this case) in the aqueous solvent ( $\mathrm{Cu}$ (II) complex + water in the present case) mixtures can be reproduced via the following equation:

$$
\begin{aligned}
q= & q_{\max } x_{B}{ }^{\prime}-\delta_{A}^{\theta}\left(x_{A}{ }^{\prime} L_{A}+x_{B}{ }^{\prime} L_{B}\right) \\
& -\left(\delta_{B}^{\theta}-\delta_{A}^{\theta}\right)\left(x_{A}{ }^{\prime} L_{A}+x_{B}{ }^{\prime} L_{B}\right) x_{B}{ }^{\prime} .
\end{aligned}
$$

The parameters $\delta_{A}^{\theta}$ and $\delta_{B}^{\theta}$ are the indexes of the BLG stability as a result of interaction with $\mathrm{Cu}(\mathrm{II})$ complex in the low and high $\mathrm{Cu}$ (II) complex concentrations, respectively. If the binding of ligand at one site increases the affinity for ligand at another site, the macromolecule exhibits positive cooperativity. Conversely, if the binding of ligand at one site lowers the affinity for ligand at another site, the protein exhibits negative cooperativity. If the ligand binds at each site independently, the binding is noncooperative. $p<1$ or $p>1$ indicates positive or negative cooperativity of macromolecule for binding with ligand, respectively; $p=1$ indicates that the binding is noncooperative. $x_{B}{ }^{\prime}$ can be expressed as follows:

$$
x_{B}^{\prime}=\frac{p x_{B}}{x_{A}+p x_{B}} \text {. }
$$

$x_{B}{ }^{\prime}$ is the fraction of the bound $\mathrm{Cu}$ (II) complex to the binding sites, and $x_{A}{ }^{\prime}=1-x_{B}{ }^{\prime}$ is the fraction of unbound $\mathrm{Cu}$ (II) complex. We can express $x_{B}$ fractions as the total $\mathrm{Cu}$ (II) complex concentrations divided by the maximum

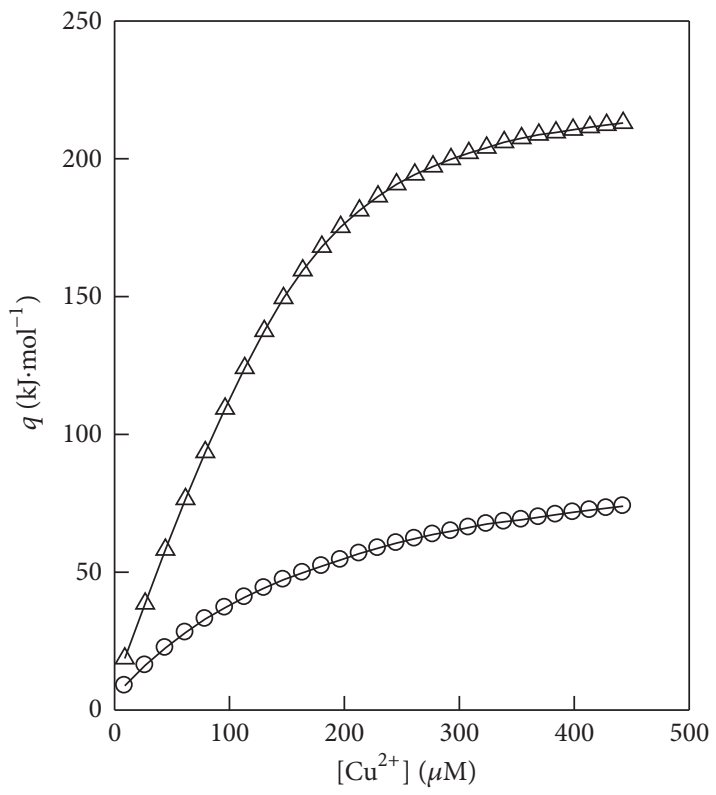

FIGURE 1: Comparison between experimental heats of interactions between BLG and copper ion at $25(O)$ and $37^{\circ} \mathrm{C}(\Delta)$ and calculated heats obtained from (1).

concentration of the $\mathrm{Cu}(\mathrm{II})$ complex upon saturation of all BLG-A as follows:

$$
x_{B}=\frac{[\mathrm{Cu}(\mathrm{II})]}{[\mathrm{Cu}(\mathrm{II})]_{\max }}, \quad x_{A}=1-x_{B} .
$$

$[\mathrm{Cu}(\mathrm{II})]$ is the concentration of $\mathrm{Cu}(\mathrm{II})$ complex, and [complex $]_{\max }$ is the maximum concentration of the $\mathrm{Cu}$ (II) complex upon saturation of all BLG. $L_{A}$ and $L_{B}$ are the relative contributions of unbound and bound $\mathrm{Cu}$ (II) complex to the heats of dilution in the absence of BLG and can be calculated from the heats of dilution of $\mathrm{Cu}$ (II) complex in buffer, $q_{\text {dilut }}$, as follows:

$$
L_{A}=q_{\text {dilut }}+x_{B}\left(\frac{\partial q_{\text {dilut }}}{\partial x_{B}}\right), \quad L_{B}=q_{\text {dilut }}-x_{A}\left(\frac{\partial q_{\text {dilut }}}{\partial x_{B}}\right) .
$$

The heats of $\mathrm{Cu}(\mathrm{II})$ complex + BLG interactions, $q$, were fitted to (1) over the whole $\mathrm{Cu}$ (II) complex compositions. In the procedure, the adjustable parameter $(p)$ was changed until the best agreement between the experimental and calculated data was approached (Figure 1). The optimized $\delta_{A}^{\theta}$ and $\delta_{B}^{\theta}$ values are recovered from the coefficients of the second and third terms of (1). The binding parameters for $\mathrm{Cu}(\mathrm{II})$ complex + BLG interactions recovered from (1) were listed in Table 1 . The agreement between the calculated and experimental results (Figure 1) is striking and gives considerable support to the use of (1).

$P$ values were calculated to be one, at different temperatures, which indicates that there are not any cooperativity in four binding sites of BLG (Table 1).

$\delta_{A}^{\theta}$ values (Table 1) for BLG + Cu(II) complex at 298 and $310 \mathrm{~K}$ are -3.49 and -9.95 , respectively, indicating that 
TABLE 1: Binding parameters for BLG $+\mathrm{Cu}(\mathrm{II})$ complex interaction recovered from (1) and (2) at different temperatures of 298 and $310 \mathrm{~K} . p=1$ indicates that the binding is noncooperative in the four binding sites. The negative values of $\delta_{A}^{\theta}$ or $\delta_{B}^{\theta}$ indicate that the low and high concentrations of $\mathrm{Cu}$ (II) complex destabilize the BLG structure. The interaction is strong as indicated by equilibrium association constants. The interaction is entropy driven, indicating that the hydrophobic forces are dominant in this interaction.

\begin{tabular}{lcc}
\hline Parameters & $T=298 \mathrm{~K}$ & $T=310 \mathrm{~K}$ \\
\hline$K_{a} / \mathrm{L} \mathrm{mol}^{-1}$ & $3.92 \times 10^{4} \pm 42$ & $1.07 \times 10^{5} \pm 42$ \\
$g$ & 4 & 4 \\
$p$ & $1.00 \pm 0.01$ & $1.00 \pm 0.01$ \\
$\delta_{A}^{\theta}$ & $-3.49 \pm 0.11$ & $-9.95 \pm 0.15$ \\
$\delta_{B}^{\theta}$ & $-5.47 \pm 0.11$ & $-22.02 \pm 0.16$ \\
$\Delta H / \mathrm{kJ} \mathrm{mol}^{-1}$ & $19.23 \pm 0.05$ & $53.82 \pm 0.25$ \\
$\Delta G / \mathrm{kJ} \mathrm{mol}^{-1}$ & $-26.38 \pm 0.04$ & $-28.88 \pm 0.08$ \\
$\Delta S / \mathrm{kJ} \mathrm{mol}^{-1} \mathrm{~K}^{-1}$ & $0.15 \pm 0.01$ & $0.27 \pm 0.02$ \\
\hline
\end{tabular}

in the low concentrations of $\mathrm{Cu}(\mathrm{II})$ complex, BLG structure has been destabilized to allow aggregation. Negative values for $\delta_{A}^{\theta}$ and $\delta_{B}^{\theta}$ at both of temperatures indicate that $\mathrm{Cu}$ (II) complex destabilizes BLG structures and is a good support for significant structural changes of BLG due to interaction with $\mathrm{Cu}(\mathrm{II})$ complex, predicted by the extended solvation model.

For a set of identical and independent binding sites to provide the number of binding sites $(g)$ and the dissociation binding constant $\left(K_{d}\right)$, a plot of $\left(\Delta q / q_{\max }\right) M_{0}$ versus $(\Delta q / q) L_{0}$ should be a linear plot by a slope of $1 / g$ and the vertical intercept of $\left(-k_{d} / g\right)$ :

$$
\frac{\Delta q}{q_{\max }} M_{0}=\frac{\Delta q}{q} L_{0} \frac{1}{g}-\frac{K_{d}}{g} .
$$

$M_{0}$ and $L_{0}$ are the concentrations of BLG and $\mathrm{Cu}(\mathrm{II})$, respectively. While $q$ represents the heat value at a certain $L_{0}$ and $q_{\max }$ indicates the heat value upon saturation of all BLG, $\Delta q=q_{\max }-q$.

The linearity of the plot has been examined by different estimated values for $q_{\max }$ to find the best value for the correlation coefficient. The small relative standard coefficient errors $( \pm 0.001)$ and the high $r^{2}$ values $(0.99999)$ indicate the best linear plot of $\left(\Delta q / q_{\max }\right) M_{0}$ against $(\Delta q / q) L_{0}$. If the optimized $q_{\max }$ is calculated per mole of BLG, then the standard molar enthalpy of binding for each binding site will be $\Delta H^{\circ}=q_{\max } / g$.

The change of the standard Gibbs free energy of binding $\left(\Delta G^{\circ}\right)$ is determined by using the association binding constant $\left(K_{a}\right)$, obtained from the inverse of $K_{d}$ value, in (6), where $R$ is the gas constant and $T$ is the absolute temperature:

$$
\Delta G^{\circ}=-R T \ln k_{a} .
$$

The change in standard entropy $\left(\Delta S^{\circ}\right)$ of this binding can be calculated as (7)

$$
\Delta S^{\circ}=\frac{\Delta H^{\circ}-\Delta G^{\circ}}{T} .
$$

All calculated thermodynamic parameters are reported in Table 1.

\section{Conclusion}

Negative values of $\delta_{A}^{\theta}$ and $\delta_{B}^{\theta}$ calculated from the extended solvation theory show that low and high concentrations of $\mathrm{Cu}(\mathrm{II})$ complex induced some structural changes in $\beta$ lactoglobulin which lead to destabilization of the protein. Previous reports represent that gelation of globular proteins results from an aggregation process, which is generally triggered by a conformational change of the protein induced by a modification of solvent conditions. In the aggregation reactions, either or both covalent (inter- and intramolecular disulphide bonds) and noncovalent bonds (hydrophobic, hydrogen, and ionic interactions) are involved. Since thermal denaturation of BLG is characterized by changes in the secondary and tertiary structures, exposing hydrophobic residues to the solvent and aggregation process due to hydrophobic interactions may subsequently take place [2430].

The above interpretations are in agreement with the solvation parameters recovered from the extended solvation model (Table 1), suggesting destabilization of BLG upon interaction with $\mathrm{Cu}(\mathrm{II})$ complex.

\section{Acknowledgment}

The financial support of Imam Khomeini International University is highly appreciated.

\section{References}

[1] S. C. Cheison, M. Schmitt, E. Leeb, T. Letzel, and U. Kulozik, "Influence of temperature and degree of hydrolysis on the peptide composition of trypsin hydrolysates of $\beta$-lactoglobulin: analysis by LC-ESI-TOF/MS," Food Chemistry, vol. 121, no. 2, pp. 457-467, 2010.

[2] P. Busti, C. A. Gatti, and N. J. Delorenzi, "Some aspects of $\beta$-lactoglobulin structural properties in solution studied by fluorescence quenching," International Journal of Biological Macromolecules, vol. 23, no. 2, pp. 143-148, 1998.

[3] K. Kuwajima, H. Yamaya, and S. Sugai, "The burst-phase intermediate in the refolding of $\beta$-lactoglobulin studied by stopped-flow circular dichroism and absorption spectroscopy," Journal of Molecular Biology, vol. 264, no. 4, pp. 806-822, 1996.

[4] F. Zsila and Z. Bikádi, "Trans-parinaric acid as a versatile spectroscopic label to study ligand binding properties of bovine $\beta$-lactoglobulin," Spectrochimica Acta A, vol. 62, no. 1-3, pp. 666-672, 2005.

[5] E. D. Brown, "Interactions of beta-lactoglobulin and alphalactalbumin with lipids: a review," Journal of Dairy Science, vol. 67, pp. 713-722, 1984.

[6] G. Dodin, M. Andrieux, and H. Al Kabbani, "Binding of ellipticine to $\beta$-lactoglobulin. A physico-chemical study of the specific interaction of an antitumor drug with a transport protein," European Journal of Biochemistry, vol. 193, no. 3, pp. 697-700, 1990.

[7] E. Dufour and T. Haertlé, "Binding affinities of $\beta$-ionone and related flavor compounds to $\beta$-lactoglobulin: effects of chemical modifications," Journal of Agricultural and Food Chemistry, vol. 38, no. 8, pp. 1691-1695, 1990. 
[8] H. M. Farrell, M. J. Behe, and J. A. Enyeart, "Binding of pnitrophenyl phosphate and other aromatic compounds by betalactoglobulin," Journal of Dairy Science, vol. 70, no. 2, pp. 252-258, 1987.

[9] J. Ono, K. Doi, K. Ogasa, and T. Nagasawa, "Discrimination of carcinogenic activity and inactivation of transforming activity of hydrocarbons, by $\beta$ lactoglobulin," Agricultural and Biological Chemistry, vol. 39, no. 11, pp. 2149-2155, 1975.

[10] H. P. Baker and H. A. Saroff, "Binding of sodium ions to betalactoglobulin,” Biochemistry, vol. 4, no. 8, pp. 1670-1677, 1965.

[11] L. Sawyer and G. Kontopidis, "The core lipocalin, bovine $\beta$ lactoglobulin," Biochimica et Biophysica Acta, vol. 1482, no. 1-2, pp. 136-148, 2000.

[12] Y. Lu and J. S. Valentine, "Engineering metal-binding sites in proteins," Current Opinion in Structural Biology, vol. 7, no. 4, pp. 495-500, 1997.

[13] J. W. F. A. Simons, H. A. Kosters, R. W. Visschers, and H. H. J. De Jongh, "Role of calcium as trigger in thermal $\beta$-lactoglobulin aggregation," Archives of Biochemistry and Biophysics, vol. 406, no. 2, pp. 143-152, 2002.

[14] A. Divsalar, A. A. Sabourya, A. A. Moosavi-Movahedi, and H. Mansoori-Torshizi, "Comparative studies on the interaction between bovine b-lactoglobulin type $\mathrm{A}$ and $\mathrm{B}$ and a new designed Pd(II) complex with anti-tumor activity at different temperatures by spectrophotometric methods," Journal of Biomolecular Structure and Dynamics, vol. 26, pp. 587-598, 2007.

[15] G. R. Behbehani, "A high performance method for thermodynamic study on the binding of copper ion and gl ycine with Alzheimer's amyliod b peptide," Journal of Thermal Analysis and Calorimetry, vol. 96, pp. 631-635, 2009.

[16] G. R. Behbehani, A. Divsalar, A. A. Saboury, F. Faridbod, and M. R. Ganjali, "A high performance method for thermodynamic study on the binding of human serum albumin with erbium chloride," Journal of Thermal Analysis and Calorimetry, vol. 96, no. 2, pp. 663-668, 2009.

[17] G. R. Behbehani, A. A. Saboury, A. F. Baghery, and A. Abedini, "Application of an extended solvation theory to study on the binding of magnesium ion with myelin basic protein," Journal of Thermal Analysis and Calorimetry, vol. 93, no. 2, pp. 479-483, 2008.

[18] G. R. Behbehani, A. Divsalar, A. A. Saboury, and A. Hekmat, "A thermodynamic study on the binding of PEG-stearic acid copolymer with lysozyme," Journal of Solution Chemistry, vol. 38, no. 2, pp. 219-229, 2009.

[19] G. R. Behbehani, A. A. Saboury, and A. F. Baghery, "A thermodynamic study on the binding of calcium Ion with myelin basic protein," Journal of Solution Chemistry, vol. 36, no. 10, pp. 1311-1320, 2007.

[20] G. R. Behbehani, A. A. Saboury, and E. Taleshi, "A comparative study of the direct calorimetric determination of the denaturation enthalpy for lysozyme in sodium dodecyl sulfate and dodecyltrimethylammonium bromide solutions," Journal of Solution Chemistry, vol. 37, no. 5, pp. 619-629, 2008.

[21] G. R. Behbehani and A. A. Saboury, "A thermodynamic study on the binding of magnesium with human growth hormone: consideration of the new extended coordination model solvation parameters," Journal of Thermal Analysis and Calorimetry, vol. 89, no. 3, pp. 857-861, 2007.

[22] G. R. Behbehani, A. A. Saboury, and E. Taleshi, "Determination of partial unfolding enthalpy for lysozyme upon interaction with dodecyltrimethylammonium bromide using an extended solvation model," Journal of Molecular Recognition, vol. 21, no. 2, pp. 132-135, 2008.

[23] G. R. Behbehani, A. A. Saboury, and E. Taleshi, "A direct calorimetric determination of denaturation enthalpy for lysozyme in sodium dodecyl sulfate," Colloids and Surfaces B, vol. 61, no. 2, pp. 224-228, 2008.

[24] B. Zhou, Z. D. Qi, Q. Xiao, J. X. Dong, Y. Z. Zhang, and Y. Liu, "Interaction of loratadine with serum albumins studied by fluorescence quenching method," Journal of Biochemical and Biophysical Methods, vol. 70, no. 5, pp. 743-747, 2007.

[25] P. Banerjee, S. Ghosh, A. Sarkar, and S. C. Bhattacharya, "Fluorescence resonance energy transfer: a promising tool for investigation of the interaction between 1-anthracene sulphonate and serum albumins," Journal of Luminescence, vol. 131, no. 2, pp. 316-321, 2011.

[26] Y. J. Hu, Y. Liu, Z. B. Pi, and S. S. Qu, "Interaction of cromolyn sodium with human serum albumin: a fluorescence quenching study," Bioorganic and Medicinal Chemistry, vol. 13, no. 24, pp. 6609-6614, 2005.

[27] S. M. Kelly and N. C. Price, "The use of circular dichroism in the investigation of protein structure and function," Current Protein and Peptide Science, vol. 1, no. 4, pp. 349-384, 2000.

[28] H. Mansuri-Torshizi, T. S. Srivastava, H. K. Parekh, and M. P. Chitnis, "Synthesis, spectroscopic, cytotoxic, and DNA binding studies of binuclear 2,2'-bipyridine-platinum(II) and -palladium(II) complexes of meso- $\alpha, \alpha^{\prime}$ - diaminoadipic and meso- $\alpha, \alpha$ '-diaminosuberic acids," Journal of Inorganic Biochemistry, vol. 45, no. 2, pp. 135-148, 1992.

[29] J. T. Yang, C. S. C. Wu, and H. M. Martinez, "Direct determination of absolute circular dichroism data and calibration of commercial instruments," Analytical Chemistry, vol. 53, no. 6, pp. 778-782, 1981.

[30] P. Manavalan and W. C. Johnson, "Variable selection method improves the prediction of protein secondary structure from circular dichroism spectra," Analytical Biochemistry, vol. 167, no. 1, pp. 76-85, 1987. 

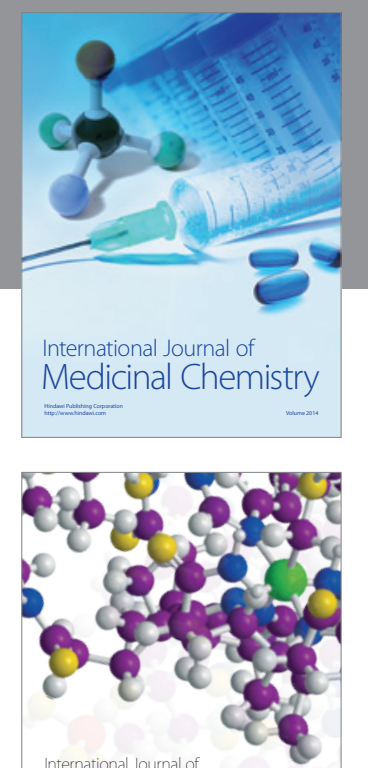

\section{Carbohydrate} Chemistry

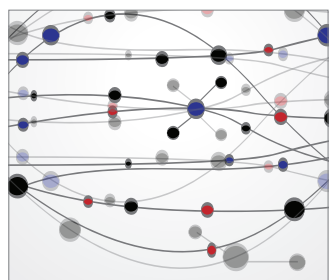

The Scientific World Journal
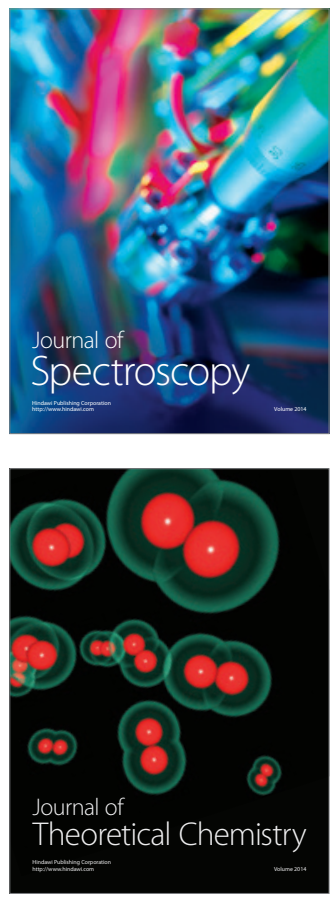
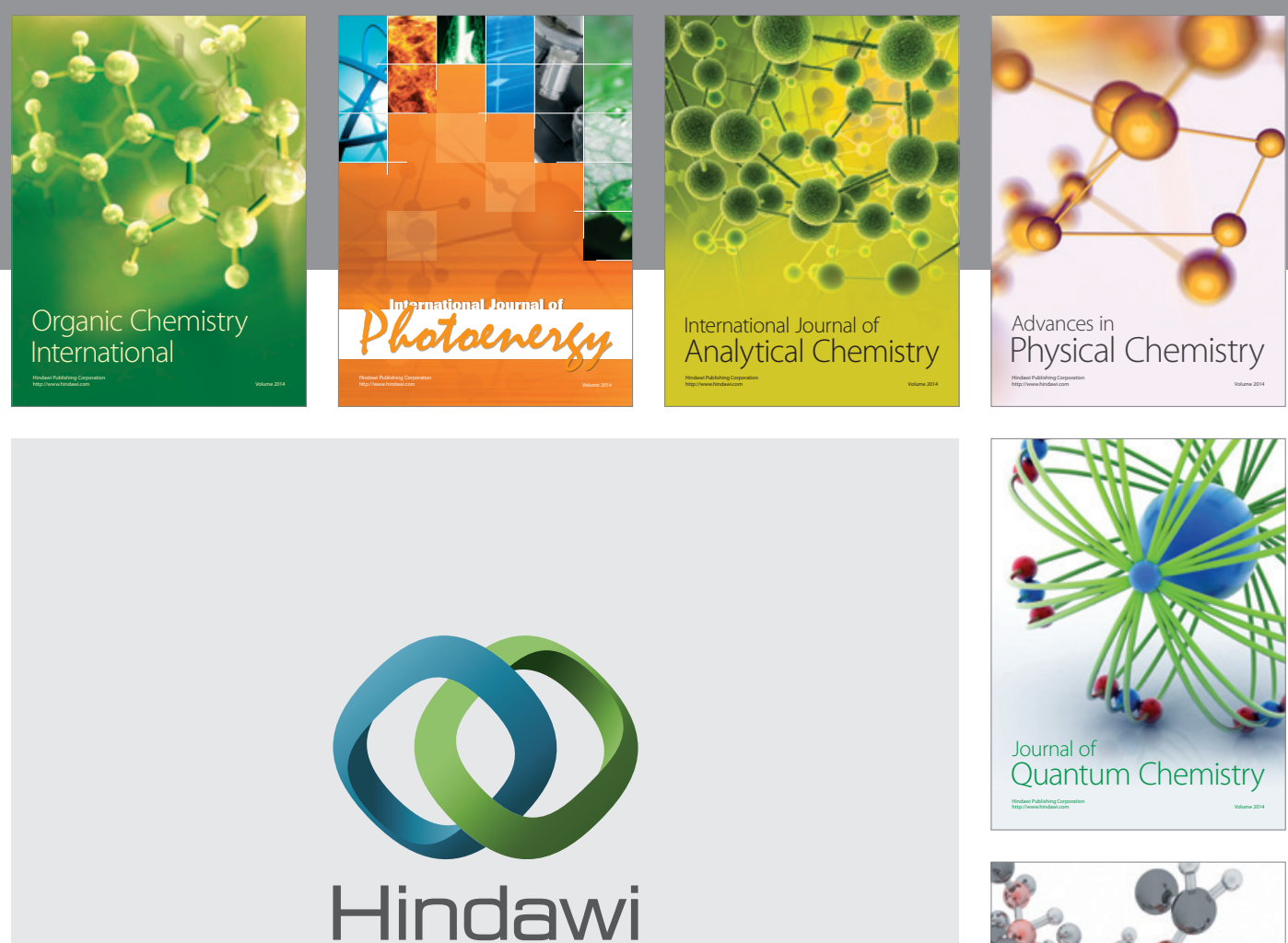

Submit your manuscripts at

http://www.hindawi.com

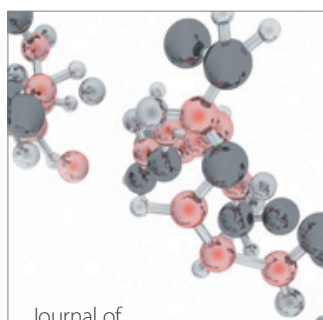

Analytical Methods

in Chemistry

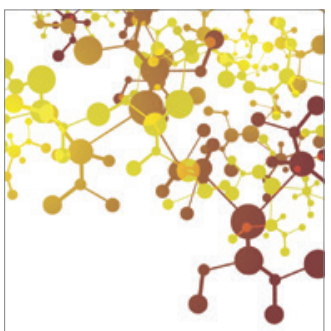

Journal of

Applied Chemistry

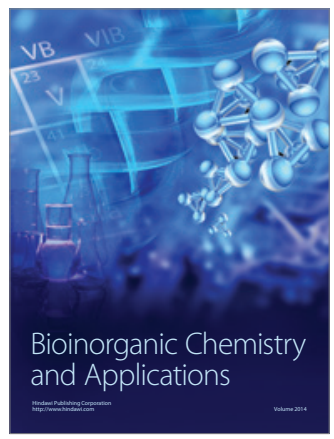

Inorganic Chemistry
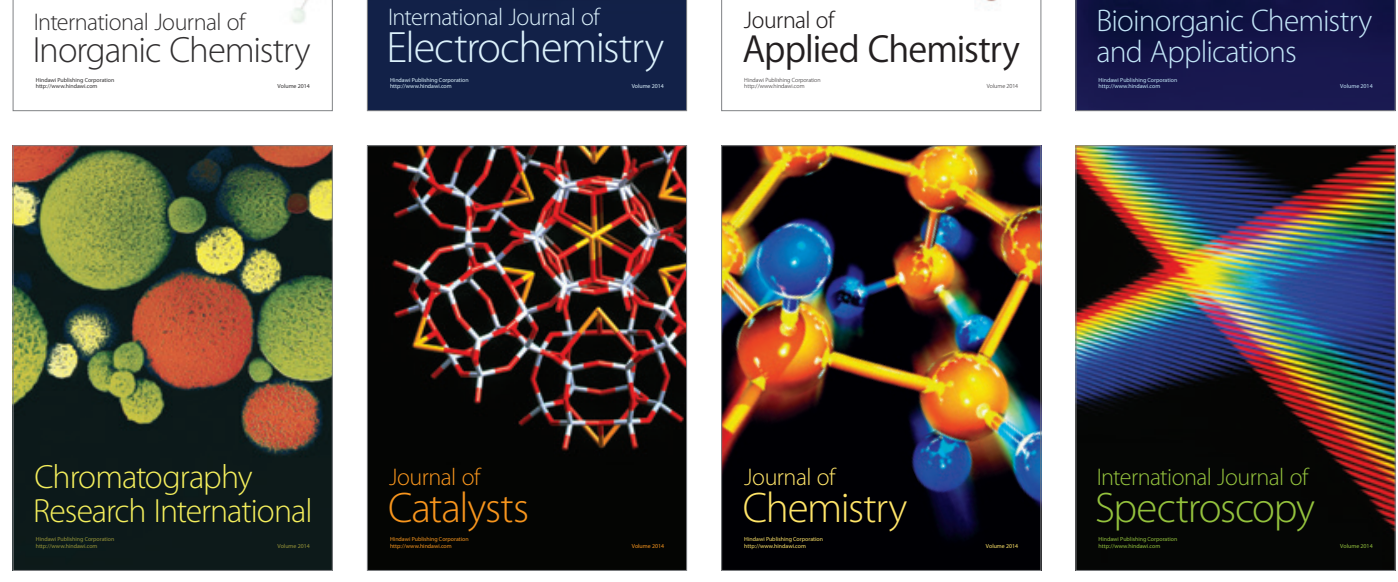